\title{
Constant Chip Volume Machining
}

\author{
Jan Hnatik, Lubos Kroft, Jan Kutlwaser \\ Faculty of Mechanical Engineering, University of West Bohemia, Pilsen, Czech Republic
}

\begin{abstract}
Nowadays there are high demands on efficiency and economy in engineering production. Therefore, CAM systems are used to prepare programs for modern productive NC machines. These systems are in most cases well prepared for roughing operations and the modern machining strategies are applied.

Anyway for product quality the finishing operations are more important. The finishing operations which combine modern methods of machining with adaptive tool path generation are usually not present. Absence of such operations is most evident when machining complex surfaces. The aim of the research was to determine the effect of a constant volume of the chip to the load of the cutting tool. The tests were performed according to the idea of constant volume removal. The result is that the effect of the constant volume of the chip influences the cutting tool load but the effect is not so significant and we must continue and develop the theory to find the correct attitude to surface finishing operations.
\end{abstract}

Keywords: cutting force; constant chip volume; surface finish; CAM; ball end mill
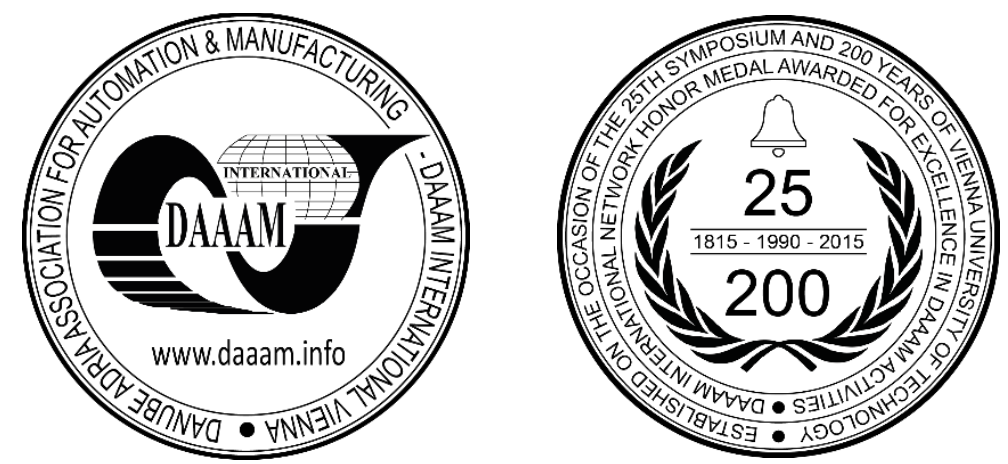

This Publication has to be referred as: Hnatik, J[an]; Kroft, L[ubos] \& Kutlwaser, J[an] (2016). Constant Chip Volume Machining, Proceedings of the 26th DAAAM International Symposium, pp.0960-0966, B. Katalinic (Ed.), Published by DAAAM International, ISBN 978-3-902734-07-5, ISSN 1726-9679, Vienna, Austria

DOI: $10.2507 / 26$ th.daaam.proceedings. 135 


\section{Introduction}

Current engineering production adapted to today's fast moving times. We are currently very quickly and productively able to produce parts in large series, but also respond quickly to changes in demand and to change production program. This trend is also adapted to modern CNC machine tools, which can not only combine several manufacturing technologies together, but also enable the production of parts in a single setup. This allows us to quickly and efficiently produce even very complex parts in a required quality. In order to respond to the change we must also be able to quickly and efficiently prepare NC-programs. That is why today CAM systems are used for the preparation of NC programs. For final quality and precision of machined surfaces the finishing operations are especially important. The final result of the machining is influenced by the method for tool paths generation, but also by the load of the cutting tool.

\begin{tabular}{|ll|}
\hline \multicolumn{2}{|l|}{ Nomenclature } \\
$\mathrm{Ft}, \mathrm{Pz}$ & tangential cutting force \\
$\sigma$ & ultimate tensile strength \\
$\mathrm{A}$ & cross sectional area of the uncut chip \\
$\mathrm{Zc}$ & number of inserts in the cut \\
$\mathrm{Cm}$ & machinability factor \\
$\mathrm{Cw}$ & tool wear factor \\
$\mathrm{Ks}$ & specific cutting resistance \\
$\mathrm{S}$ & feed per revolution \\
$\mathrm{T}$ & depth of cut \\
$\mathrm{Kr}$ & correction factor for rake angle \\
$\mathrm{Kw}$ & correction factor for tool wear \\
$\mathrm{Kv}$ & correction factor for cutting speed \\
\hline
\end{tabular}

\section{Finishing operations in CAM systems}

CAM system development in recent years has focused primarily on roughing operations. CAM systems usually contain operations which support advanced machining strategies as HPC, HFC and more [1]. These operations can also adaptively adjust tool path [2]. This makes them possible to quickly and efficiently remove the material of the rough stock.

The aim of roughing is to remove as much material as possible in the shortest time, but the quality and precision of the machined surfaces are not so important. In contrast, finishing operations give the use properties of the resulting surface finish. It is possible to choose several finishing operations in CAM systems. Basic finishing operations are divided according to the slope of the surface. Unfortunately, CAM systems usually miss the possibility to combine modern machining strategies and tool paths generation adaptively according to the surface shape. It can cause a problem when the slope of the machined surface dramatically changes.

We can now divide the finishing operations into three basic groups. In the first group, there are the operations for vertical walls and surfaces with a small slope angle. These operations create the tool path in the axial direction. The user sets the axial step of the tool path and the CAM system calculates the radial step accordingly [3].

The next group of finishing operations is used for machining of the pocket bottom or shallow surfaces. The basic parameter is the radial step which defines the basic side step of the tool path. CAM system calculates the axial position of the tool path according to the shape of the surface.

The third group defines the tool path according to the surface normal direction which is suitable especially for the surfaces where the slope changes from vertical to horizontal direction. The CAM systems usually combine both approaches mentioned above. The definition of the operation then contains both, radial and axial side step. Some systems also compute the tool path according to the scallop height or to the constant step along defined 3D curve (fig. 2).

a

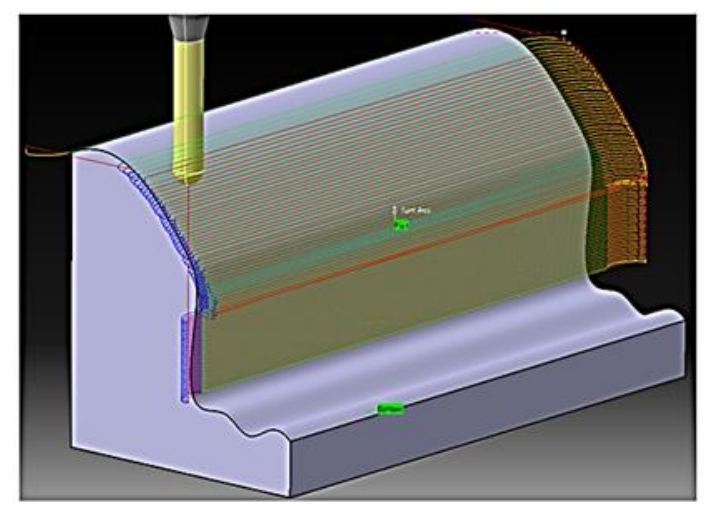

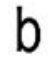

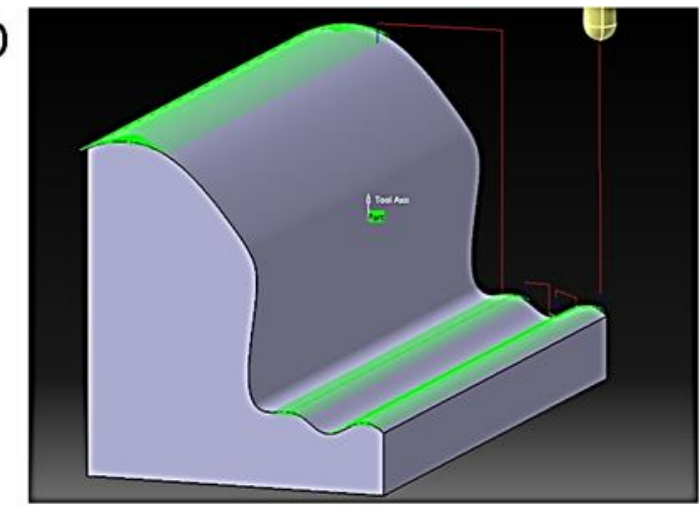

Fig. 1. Vertical (a) and horizontal (shallow) (b) surface finish 


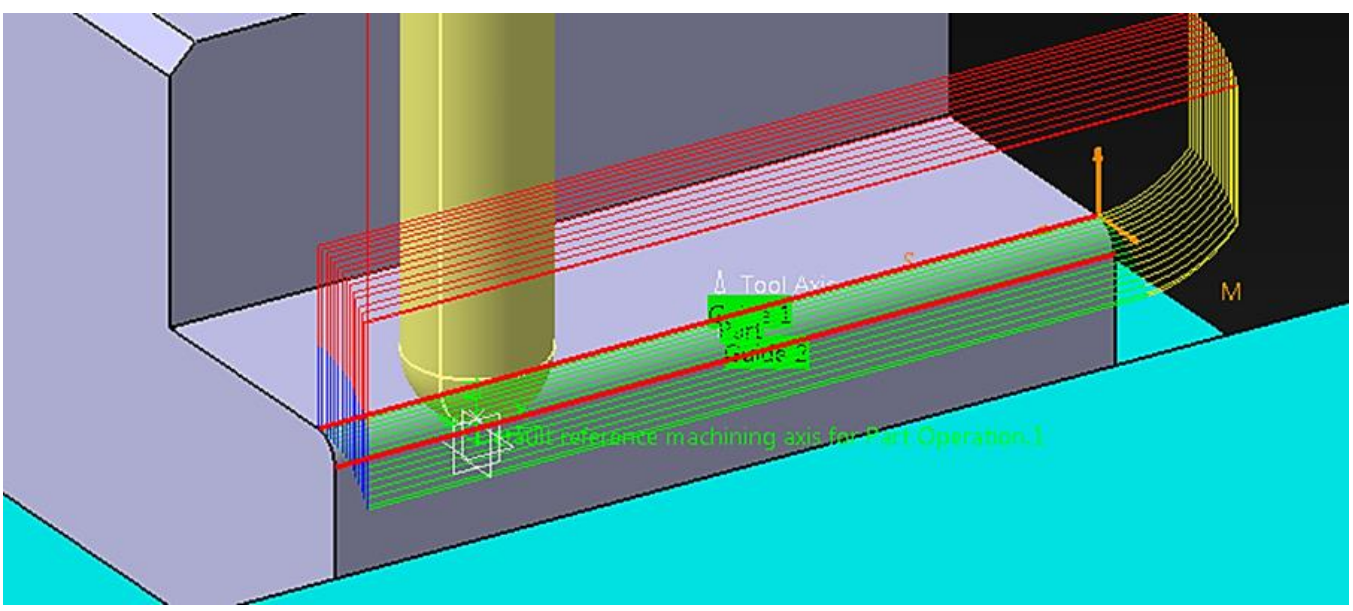

Fig. 2. Function CONTOUR-DRIVEN used for fillet finishing, CATIA

These basic strategies allow the user to choose a proper surface finish operation. Anyway, the tool path generated by these strategies is not optimal. This is obvious by machining complicated shape surfaces (fig.3). During the change of the slope several parameters change at the same time and it influences the quality of the finished surface [4]. This raises a kind of distrust of the CAM users and they usually set up smaller side step in radial or axial direction to reach required surface quality. This leads to a smaller machining productivity.

Bull nose and ball nose cutters are usually used for surface finishing. The change of surface slope changes the contact point of the cutter and accordingly varies several parameters. First the cross section of the chip changes and it also causes the change of the cutting force. This can result into the cutting tool chatter and lower quality of the finished surface. The change of the contact point also changes the effective cutting speed. Again this can negatively influence the cutting process.

According to the current analysis the cutting force respectively is tangential component is an important parameter of the cutting process. The change of this cutting force may affect the quality of the finished surface.

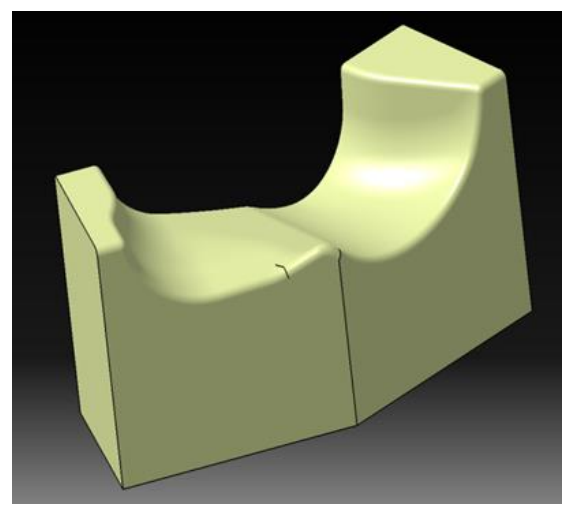

Fig. 3. Example of complicated shape surface

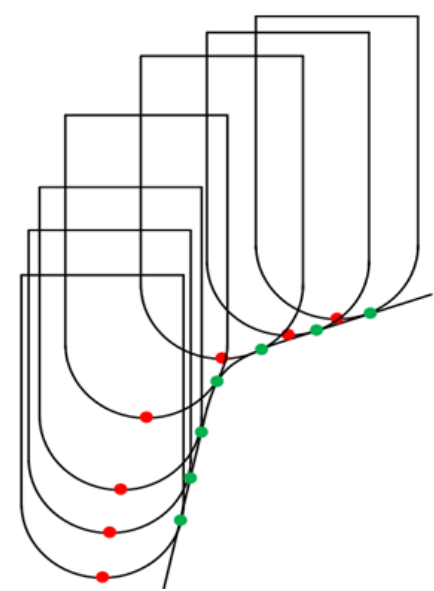

Fig. 4. Change of the contact point according to the surface slope 


\section{Complex surface machining}

On the basis of the knowledge mentioned above the purpose of the research was to propose a strategy which can generate such a tool path that the cutting force is being kept constant even on a surface with variable slope. To be able to solve this problem, it is necessary to understand the complex behaviour of the finish cutting process. As an initial analysis the practical test was performed. The reason of this test was to identify the change of the cutting force according to the change of the slope and the side step. The reason of the change of the side step is to identify the cutting force change according to the chip volume.

The initial test was performed on the specimen made of 1.2379 steel. This is a type of high alloyed chrome molybdenum vanadium steel. The specimen was machined by the ball end mill with interchangeable insert (Iscar ballplus with HCM insert). The main parameter was the slope of the surface. At the beginning three slopes were defined $-20,40$ and 55 degrees. The side step varied from $0.05 \mathrm{~mm}$ to $1.45 \mathrm{~mm}$.

The result of the test is shown in fig.5. The resulting graph shows that the cutting force changes linearly according to the side step in all three slopes. It is also possible to see that the cutting force reaches the smallest values on the 20 degrees surface; the highest values are reached on the 40 degrees surface.

Another set of test cuts proved also a linear dependence of the cutting force and depth of cut. This corresponds also to the cutting force calculation equations based on ultimate tensile strength [5] or specific cutting resistance [6]. The tangential cutting force is also linearly dependent to the cross sectional area of the chip in both equations:

$$
\begin{aligned}
& F_{t}=\sigma A Z_{C} C_{m} C_{w}[5] \\
& P_{Z}=K_{Z} s t K_{r} K_{w} K_{v}
\end{aligned}
$$

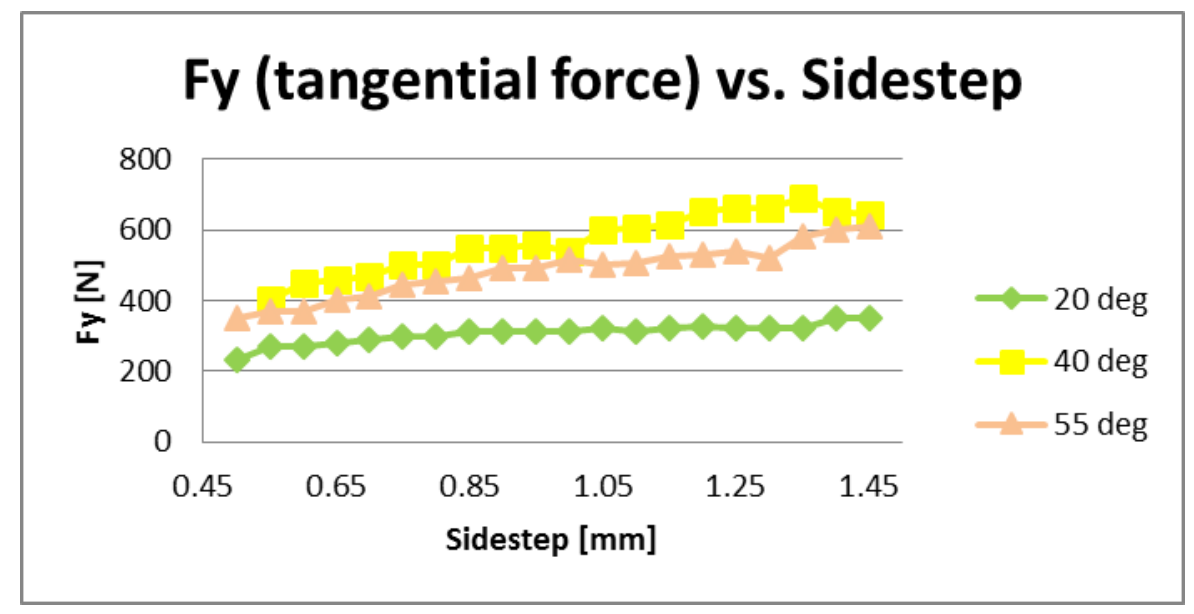

Fig. 5. The dependency of the tangential cutting force on the side step

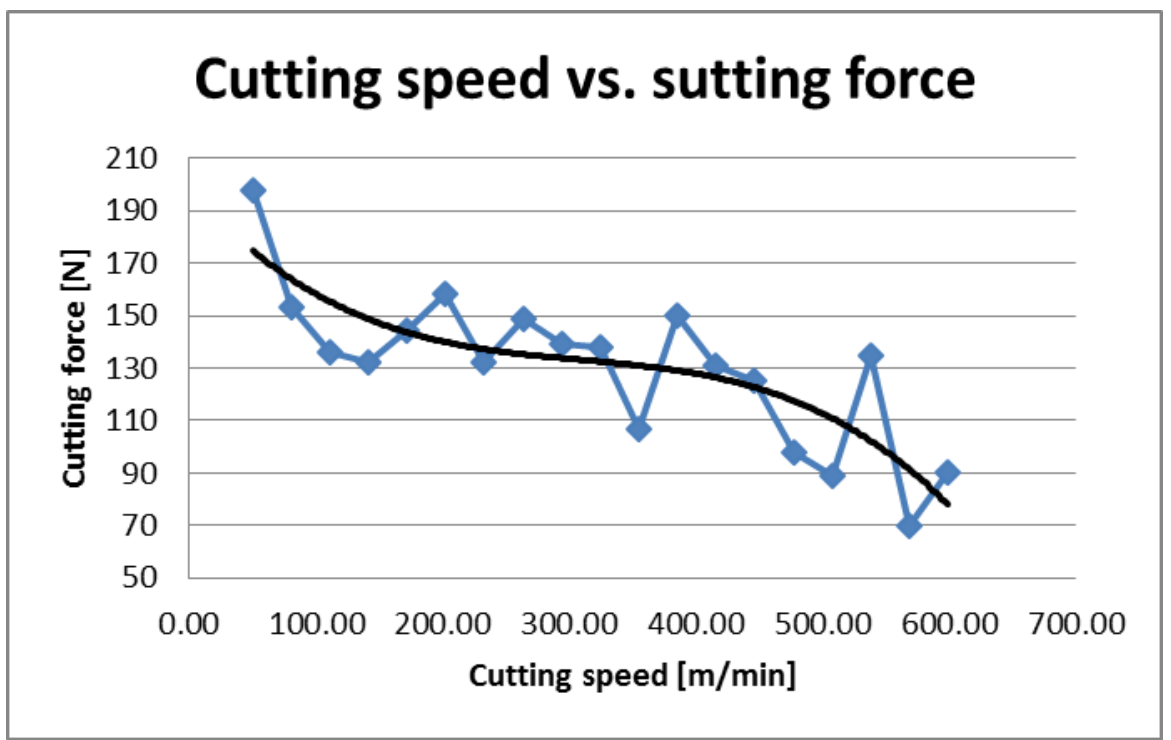

Fig. 6. The dependency of the cutting force on the cutting speed 
Another performed test compared the cutting force according to the cutting speed while the chip cross section was kept constant. The result shows that the cutting force decreases together with increasing cutting speed (see fig. 6). This result also corresponds with general knowledge which was first introduced by C. Salomon in 1931 [7].

The main idea of the next test was to keep the chip volume constant and so keep the cutting force of the finishing tool constant. The test was performed on a rotational surface with variable slope which formed a closed pocket (see fig. 7). The tool path was calculated so the chip volume and feed were constant and the surface had a constant material offset of $0.5 \mathrm{~mm}$. This test should show the behaviour of the cutting force on a surface with variable slope and to compare the strategy with constant chip volume to a standard finishing operation in CAM system. The tool path with constant chip volume was created manually because this strategy is not offered by CAM systems.

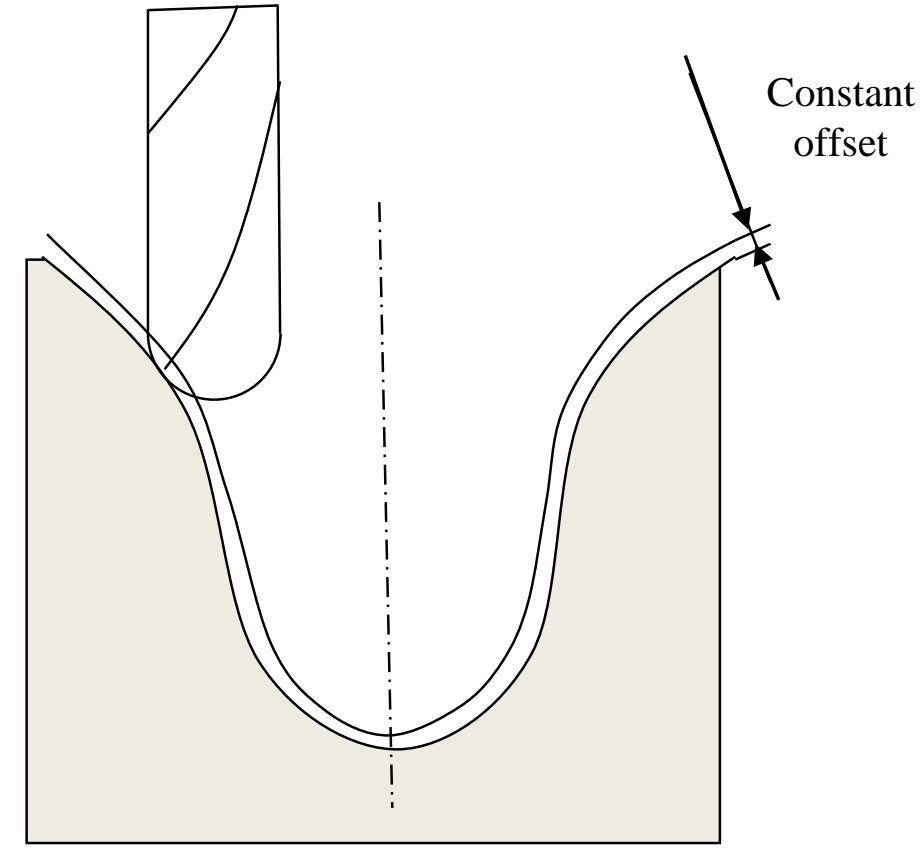

Fig. 7. Test surface with constant offset

The second type of machining strategy used a constant axial step. The test was repeated with variable cutting speeds 100,350 and $600 \mathrm{~m} / \mathrm{min}$. The results of the test are shown in the fig. 8 and fig. 9 , where $\mathrm{x}$ axis shows time in seconds and $y$ axis is the tangential force in Newtons.

The graphs in fig. 8 and fig. 9 show that the cutting force in both cases is very similar and varies together with time. In case of strategy with constant chip volume the values of the cutting force are strongly limited (time range $150-$ $160 \mathrm{~s}$ ) in comparison with the peak value in case of Constant $\mathrm{Z}$ (time range $105-115 \mathrm{~s}$ ). This is the time range which corresponds in both cases with cutting in the position of the lower radius of the pocket, where the radius of the surface and radius of the cutting tool are equal.

The similar values of the cutting force (except of the time ranges mentioned above) clearly show that the influence of the chip volume is not as important as expected. Vice versa, the cutting force is highly influenced by the slope angle of the surface. This effect may be caused by varying effective cutting force [8]. To prove this idea it is necessary to perform and evaluate further tests which could define the desired adaptive strategy of surface finishing.

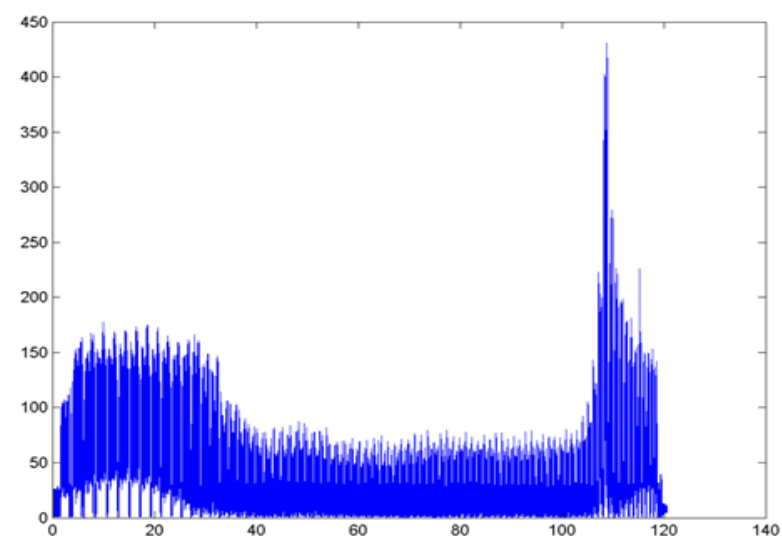

Fig. 8. Constant $\mathrm{Z}-\mathrm{vc}=600 \mathrm{~m} / \mathrm{min}$ 


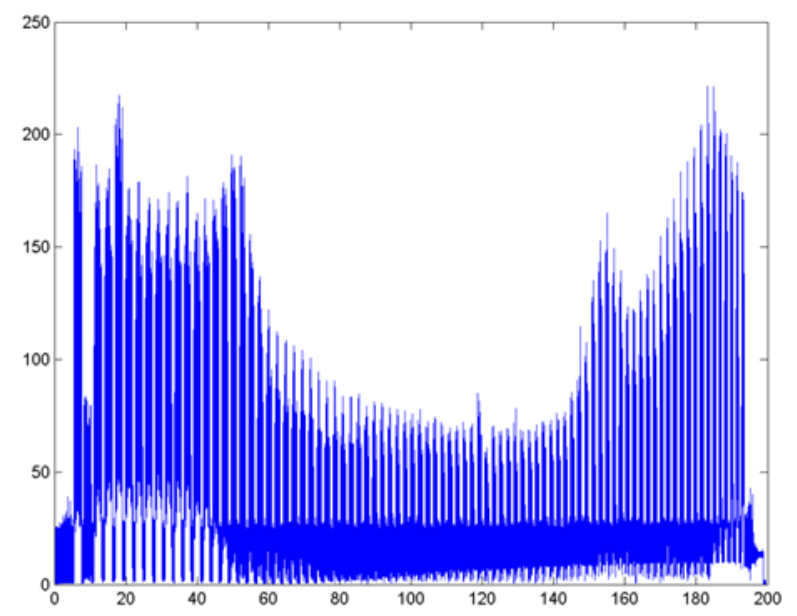

Fig. 9. constant chip volume $-\mathrm{vc}=600 \mathrm{~m} / \mathrm{min}$

\section{Quality of finished surface}

The aim of the finishing operation is an effective machining of the surfaces in a desired quality. For effective finishing the uniform quality of the surface is needed. The constant chip volume was used for tool side step calculation. The problem is that the constant chip volume depends not only on the tool path side step but also on the machined surface curvature. The side step is different in case of flat surface and it is different in case of the surface with a curvature equal or nearly equal to the ball end mill radius. This causes, that he side step varies and the final surface quality is not uniform. It means that the quality of the surface significantly decreases in flat regions and the programmer would be forced to set a small chip volume. The situation would be the same as in case of recent strategies in CAM systems.

This is the reason, why the constant chip volume cutting is not very effective for finishing operations.

\section{Conclusion}

The main idea of the research is to find an effective strategy of surface finish to reach homogenous quality of the machined surface. The surface quality is mainly given by the side step of the tool path. The strategy of cutting with constant chip volume was used to secure this demand and the side step of the toolpath was calculated according to the condition of constant chip volume.

According to the performed tests it is possible to state that the constant chip volume cutting causes more uniform cutting tool load but at the same time it is not possible to secure required quality of the finished surface. So, this strategy of cutting is not suitable for tool path side step calculation. There is still a need to develop another algorithm to calculate an optimal tool path for surface finishing. Anyway, the prediction of the cutting force based on the chip volume can be used as a tool to check the cutting force in the CAM simulation and to help to protect the cutting tool and work piece surface form damage caused by tool overload.

Because the constant chip volume strategy showed that it is not appropriate for surface finish operation it is needed to focus on other forms of tool path calculation. The side step calculation should be defined especially by the surface properties as surface curvature and position of the contact point of the cutting tool.

\section{Acknowledgements}

The present contribution has been prepared under project LO1502 'Development of the Regional Technological Institute " under the auspices of the National Sustainability Programme I of the Ministry of Education of the Czech Republic aimed to support research, experimental development and innovation.

\section{References}

[1] H. Perez, E. Diezb, J. Perezc, A. Vizan, Analysis of Machining Strategies for Peripheral Milling, Procedia Engineering, Volume 63, 2013, Pages 573-581, The Manufacturing Engineering Society International Conference, MESIC 2013.

[2] Marek Sadílek, CAM systémy v obrábění I. (CAM systems and machining I.), VŠB - TU Ostrava, Ostrava, 2008.

[3] AMT SOFTWARE. 3D Machining Strategies: Comprehensive Suite of 3D Machining Strategies, http://www.prospectornc.com/3DMachiningStrategies.htm, 2013.

[4] Tomáš Vopát, Jozef Peterka, Vladimír Šimna, Marcel Kuruc, The Influence of Different Types of Copy Milling on the Surface Roughness And Tool Life of End Mills, Procedia Engineering, Volume 100, 2015, Pages 868-876, 25th DAAAM International Symposium on Intelligent Manufacturing and Automation, DAAAM 2014. 
[5] Edmund Isakov, Engineering Formulas for Metalcutting, Industrial Press, Inc., New York, 2004, p.62.

[6] HMT, Production Technology, Tata McGraw-Hill Publishing Company Limited, New Delhi, 2008.

[7] J.M. Longbottom, J.D. Lanham, A review of research related to Salomon's hypothesis on cutting speeds and temperatures, International Journal of Machine Tools and Manufac-ture, Volume 46, Issue 14, November 2006, Pages 1740-1747.

[8] Vopát Tomas, Peterka Jozef, Kováč Mario, Buranský Ivan, The Wear Measurement Process of Ball Nose end Mill in the Copy Milling Operations, Procedia Engineering, Volume 69, 2014, Pages 1038-1047, 24th DAAAM International Symposium on Intelli-gent Manufacturing and Automation, 2013. 